Pacific Journal of Mathematic 


\section{CONCERNING THE DOMAINS OF GENERATORS OF LINEAR SEMIGROUPS}

\section{J. W. SpellmanN}

Let $S$ denote a Banach space over the real numbers. Let $A$ denote the infinitesimal generator of a strongly continuous semigroup $T$ of bounded linear transformations on $S$. It is known that the Riemann integral $\int_{a}^{b} T(x) p d x$ is in the domain of $A$ (denoted by $D(A)$ ) for each $p$ in $S$ and each nonnegative number interval $[a, b]$. This paper develops sufficient conditions on nonnegative continuous functions $f$ and on elements $p$ in $S$ in order that the Riemann integral $\int_{a}^{b} T(f(x)) p d x$ be an element of the domain of $A$.

2. A change of variable technique. A change of variable theorem may sometimes be used to transform

$$
\int_{a}^{b} T(f(x)) p d x \text { to } \int_{c}^{d} T(x)\left(f^{-1}\right)^{\prime}(x) p d x
$$

where $f^{-1}$ denotes the inverse of $f$. This motivates the first theorem.

THEOREM 1. Suppose $p \in S, 0 \leqq c<d$ and $h$ is a real valued function which has a continuous derivative on $[c, d]$. Then

$$
\int_{c}^{d} T(x) h(x) p d x
$$

is in $D(A)$ and

$$
A \int_{c}^{d} T(x) h(x) p d x=h(d) T(d) p-h(c) T(c) p-\int_{c}^{d} T(x) h^{\prime}(x) p d x
$$

Proof.

$$
\begin{aligned}
& \lim _{\varepsilon \rightarrow 0} \varepsilon^{-1}[T(\varepsilon)-T(0)] \int_{c}^{d} T(x) h(x) p d x \\
= & \lim _{\varepsilon \rightarrow 0} \varepsilon^{-1} \int_{c+\varepsilon}^{d+\varepsilon} T(x) h(x-\varepsilon) p d x-\lim _{\varepsilon \rightarrow 0} \varepsilon^{-1} \int_{c}^{d} T(x) h(x) p d x \\
= & \lim _{\varepsilon \rightarrow 0} \varepsilon^{-1} \int_{d}^{d+\varepsilon} T(x) h(x-\varepsilon) p d x-\lim _{\varepsilon \rightarrow 0} \varepsilon^{-1} \int_{c}^{c+\varepsilon} T(x) h(x) p d x \\
& -\lim _{\varepsilon \rightarrow 0} \varepsilon^{-1} \int_{c+\varepsilon}^{d} T(x)[h(x)-h(x-\varepsilon)] p d x \\
= & h(d) T(d) p-h(c) T(c) p-\int_{c}^{d} T(x) h^{\prime}(x) p d x .
\end{aligned}
$$


The second theorem then follows as an immediate consequence of Theorem 1.

Theorem 2. Suppose $p \in S, 0 \leqq a<b, 0 \leqq c<d$ and $f$ is $a$ continuous function from $[a, b]$ to $[0, \infty]$ so that

(i ) $\left(f^{-1}\right)^{\prime \prime}$ is continuous on $[c, d]$ and

(ii ) $\int_{a}^{b} T(f(x)) p d x= \pm \int_{c}^{d} T(x)\left(f^{-1}\right)^{\prime}(x) p d x$. Then $\int_{a}^{b} T(f(x)) p$ is in $D(A)$ and

$$
\begin{aligned}
A \int_{a}^{b} T(f(x)) p d x= & \pm\left[\left(f^{-1}\right)^{\prime}(d) T(d) p-\left(f^{-1}\right)^{\prime}(c) T(c) p\right. \\
& \left.-\int_{c}^{d} T(x)\left(f^{-1}\right)^{\prime \prime}(x) p d x\right]
\end{aligned}
$$

Example 1. Suppose $0 \leqq a<b, m$ and $k$ are real numbers so that $m \neq 0$ and $m x+k \geqq 0$ for all $x \in[a, b]$. Then $\int_{a}^{b} T(m x+k) p d x$ is in $D(A)$ and

$$
A \int_{a}^{b} T(m x+k) p d x=\frac{1}{m}[T(m b+k) p-T(m a+k) p] .
$$

It is noted that Theorem 2 says nothing about $\int_{a}^{b} T(f(x)) p d x$ being in $D(A)$ if $\int_{a}^{b} T(f(x)) p d x$ does not equal $\pm \int_{c}^{b} T(x)\left(f^{-1}\right)^{\prime}(x) p d x$ or if $\left(f^{-1}\right)^{\prime \prime}$ is not continuous on $[c,, d]$. A different approach is considered in the next section which sometimes allows for such exceptions.

3. A closed operator technique. In this section, the restrictions imposed on the function $f$ in the hypothesis of Theorem 2 will be relaxed. In accomplishing this, additional restrictions will be placed on the point $p$ mentioned in Theorem 2. The fact that the infinitesimal generator $A$ of the semigroup $T$ is a closed linear operator implies the next theorem.

Theorem 3. Suppose $p \in D(A), 0 \leqq a<b$ and $f$ is a continuous function from $[a, b]$ to $[0, \infty)$. Then

$$
\int_{a}^{b} T(f(x)) p d x
$$

is in $D(A)$ and

$$
A \int_{a}^{b} T(f(x)) p d x=\int_{a}^{b} T(f(x)) A p d x .
$$


The fourth theorem follows from Example 1, properties of continuous real valued functions and the fact that the space $S$ is complete.

Theorem 4. Suppose $p \in S, 0 \leqq a<b$ and $f$ is a continuous function from $[a, b]$ to $[0, \infty)$. Suppose $\left\{f_{n}\right\}_{n=1}^{\infty}$ is a sequence of piecewise linear functions, each from $[a, b]$ to $[0, \infty)$, which converge uniformly to $f$ on $[a, b]$. Then $\int_{a}^{b} T(f(x)) p d x$ is in $D(A)$ whenever $\left\{A \int_{a}^{b} T\left(f_{n}(x)\right) p d x\right\}_{n=1}^{\infty}$ is a Cauchy sequence in $S$. In this case

$$
A \int_{a}^{b} T(f(x)) p d x=\lim _{n \rightarrow \infty} A \int_{a}^{b} T\left(f_{n}(x)\right) p d x .
$$

In order to develop useful corollaries to Theorem 4, we make the following definitions.

Definition 1. Suppose $K=\left\{x_{j}\right\}_{j=0}^{n}$ is a partition of $[a, b]$ and $f$ is a continuous real valued function defined on $[a, b]$. Then $[f ; K]$ denotes the piecewise linear function defined on $[a, b]$ by the rule

$$
[f ; K](x)=\left[f\left(x_{j}\right)-f\left(x_{j-1}\right)\right]\left[\left(x_{j}-x_{j-1}\right)^{-1}\right]\left[x-x_{j-1}\right]+f\left(x_{j-1}\right)
$$

for $x \in\left[x_{j-1}, x_{j}\right], j=1,2, \cdots, n$.

Definition 2. Suppose $0<\alpha \leqq 1$. Then $\Delta(\alpha)$ denotes the subset of $S$ which contains $p$ if and only if for each positive number $r$, there is a positive number $M(r)$ so that

$$
\|T(x) p-p\|<x^{\alpha} M(r)
$$

for all $x \in[0, r]$.

It is noted that $D(A) \subseteq \Delta(\alpha)$ for each $\alpha \in[0,1]$. However, the next example illustrates that $\Delta(1)$ may not be a subset of $D(A)$.

ExAmple 2. Let $S$ denote the Banach space of real valued functions which are bounded and uniformly continuous on $[0, \infty)$. For each $f \in S$, let

$$
\|f\|=\operatorname{lub}_{x \geqq 0}|f(x)| .
$$

Let $T$ be the strongly continuous linear semigroup defined on $S$ by the rule

$$
[T(\beta) f](x)=f(\beta+x)
$$

for each pair $(\beta, x)$ in $[0, \infty) \times[0, \infty)$. Then $f$ is in $D(A)$ if and only if $f^{\prime}$ is in $S$. 
Let $g$ be the function is $S$ so that

$$
g(x)=\left\{\begin{array}{cl}
1-x & \text { if } x \in[0,1] \\
0 & \text { if } x \geqq 1
\end{array} .\right.
$$

Then $g$ is in $\Delta(1)$, but $g$ is not in $D(A)$.

Definition 3. Suppose $0 \leqq a<b$ and each of $P_{1}=\left\{x_{j}\right\}_{j=0}^{n}$ and $P_{2}=\left\{t_{k}\right\}_{k=0}^{m}$ is a partition of $[a, b]$. The statement the $P_{2}$ is a doubling refinement of $P_{1}$ means that

(1) $m=2 n$ and

(2) $t_{2 j}=x_{j}$ for $j=0,1, \cdots, n$.

Definition 4. Suppose $0 \leqq a<b, \alpha \in[0,1], f:[a, b] \rightarrow[0, \infty)$ and $P=\left\{P_{n}\right\}_{n=1}^{\infty}=\left\{\left\{a_{n k}\right\}_{k=0}^{2 n}\right\}_{n=1}^{\infty}$ is a sequence of partitions of $[a, b]$ so that $P_{n+1}$ is doubling refinement of $P_{n}$ for each positive integer $n$. The statement that $f$ satisfies condition $S(\alpha)$ relative to $P$ means that

(1) $\left\{\left[f ; P_{n}\right]\right\}_{n=1}^{\infty}$ converges uniformly to $f$ on $[a, b]$,

(2) $f\left(a_{n k+1}\right) \neq f\left(a_{n k}\right)$ for $n=1,2, \ldots$ and $k=0,1, \ldots, 2^{n}-1$,

(3) $\sum_{n=1}^{\infty} \sum_{k=0}^{2^{n}-1}\left|\Delta f_{n, k}-\Delta f_{n+1,2 k}\right|\left|f\left(a_{n+1,2 k+1}\right)-f\left(a_{n k}\right)\right|^{\alpha} \quad$ converges and

(4) $\sum_{n=1}^{\infty} \sum_{k=0}^{2^{n}-1}\left|\Delta f_{n, k}-\Delta f_{n+1,2 k+1}\right|\left|f\left(a_{n, k+1}\right)-f\left(a_{n+1,2 k+1}\right)\right|^{\alpha}$ converges where $\Delta f_{n, k}=\left[a_{n, k+1}-a_{n, k}\right]\left[f\left(a_{n, k+1}\right)-f\left(a_{n, k}\right)\right]^{-1}$ for $n$ a positive integer, $k$ an integer in the number interval $\left[0,2^{n}-1\right]$.

The next theorem is a useful corollary to Theorem 4 .

THEOREM 5. Suppose $0 \leqq a<b, 0<\alpha \leqq 1$,

$$
P=\left\{P_{n}\right\}_{n=1}^{\infty}=\left\{\left\{a_{n k}\right\}_{k=0}^{2^{n}-1}\right\}_{n=1}^{\infty}
$$

a sequence of partitions of $[a, b]$ so that $P_{n+1}$ is a doubling refinement of $P_{n}$ for each positive integer $n$. Suppose $f:[a, b] \rightarrow[0, \infty)$ is continuous and satisfies condition $S(\alpha)$ relative to $P$. Then if

$$
p \in \Delta(\alpha), \int_{a}^{b} T(f(x)) p d x
$$

is in $D(A)$ and

$$
A \int_{a}^{b} T(f(x)) p d x=\lim _{n \rightarrow \infty} A \int_{a}^{b} T\left(\left[f ; P_{n}\right](x)\right) p d x .
$$

Proof. The proof of Theorem 5 follows from Example 1 and Theorem 4.

The next theorem relaxes conditions on the function $f$ mentioned 
in Theorem 2. The conditions imposed on point $p$, however, will be more restrictive.

Theorem 6. Suppose $0 \leqq a<b, p \in \Delta(1), f:[a, b] \rightarrow[0, \infty)$ so that

(1) $f^{\prime}$ is continuous on $[a, b]$

(2) $\left|f^{\prime}(x)\right|>0$ for all $x \in[a, b]$

(3) $f^{\prime \prime}$ is bounded on $[a, b]$.

Then $\int_{a}^{b} T\left(f^{\prime}(x)\right) p d x$ is in $D(A)$.

Proof. Let $P=\left\{P_{n}\right\}_{n=1}^{\infty}=\left\{\left\{a_{n k}\right\}_{k=0}^{2 n}\right\}_{n=1}^{\infty}$ be a sequence of partitions of $[a, b]$ so that $a_{n, k}=a+\left(k 2^{-2}\right)(b-a)$. Then $P_{n+1}$ is a doubling refinement of $P_{n}$ for each positive integer $n$ and $\left\{\left[f ; P_{n}\right]\right\}_{n=1}^{\infty}$ converges uniformly to $f$ on $[a, b]$. The mean value theorem and the hypothesis on $f$ imply $f$ satisfies conditive $S(1)$ relative to $P$. An application of Theorem 4 completes the proof.

It is noted that the same sequerce $P$ of partitions used in the proof of Theorem 6 may be used to show that $\int_{a}^{b} T(f(x)) p d x$ is $D(A)$ whenever $p \in \Delta(1)$ and $f$ is a nonconstant and nonnegative polynomial whose coefficients are either all positive or all negative.

The next example shows that hypothesis (i) of Theorem 2 is not a necessary condition for $\int_{a}^{b} T\left(f^{\prime}(x)\right) p d x$ to be in $D(A)$.

ExAmple 3. Suppose $0<b, \beta>0, m$ is a positive integer, $1-$ $1 / m<\alpha \leqq 1$ and $p \in \Delta(\alpha)$. Let $f(x)=\beta x^{m}$ for $x \geqq 0$. Then $\left(f^{-1}\right)^{\prime \prime}$ is not continuous at 0 . However, using the same sequence $P$ as in the proof of Theorem $6, \int_{a}^{b} T(f(x)) p d x$ may be shown to be in $D(A)$.

The fourth example will indicate that hypothesis (ii) of Theorem 2 is not necessary for $\int_{a}^{b} T\left(f^{\prime}(x)\right) p d x$ to be in $D(A)$.

ExAmple 4. Let $C$ denote Cantor's ternary set (see p. 329 of [3]). For each $x$ in the interval $[0,1]$, let

$$
C_{x}=\operatorname{lub}(C \cap[0, x]) \text {. }
$$

Let $w$ be the furction defined on $[0,1]$ by the rule

$$
w(x)={ }_{2}\left(C_{x} \cdot 2^{-1}\right)
$$

where ${ }_{2}\left(C_{x} \cdot 2^{-1}\right)$ denotes the binary form of $\left(C_{x} \cdot 2^{-1}\right)$. Hille and Tamarkin, in [2], have shown $w$ to be continuous, nondecreasing and to have a zero derivative almost everywhere on $[0,1]$. Let $f$ be the function so that 


$$
f(x)=x+w(x) \text { for } x \in[0,1] \text {. }
$$

Then $f$ is a strictly increasing function which fails to be absolutely continuous on $[0,1]$. Thus, one would not expect the second condition of the hypothesis of Theorem 2 to hold. However, $\int_{0}^{1} T(f(x)) p$ is in $D(A)$ whenever $p$ is in $\Delta(1)$. This is seen by using Theorem 4 and proper choice of partitions of $[0,1]$. Let

$$
\begin{aligned}
M_{0} & =\{0\}, N_{0}=\{1\} \\
M_{1} & =\left\{{ }_{3} .022 \cdots\right\}^{1} \\
N_{1} & =\left\{{ }_{3} .200 \cdots\right\} \\
Q_{1} & =\left\{{ }_{3} .111 \cdots\right\} .
\end{aligned}
$$

For each integer $m \geqq 2$, let

$$
\begin{aligned}
M_{m} & =\left\{\left\{_{3} . a_{1} \cdots a_{m-1} 022 \cdots\right\}\right. \\
N_{m} & =\left\{{ }_{3} . a_{1} \cdots a_{m-1} 200 \cdots\right\} \\
Q_{m} & =\left\{{ }_{3} . a_{1} \cdots a_{m-1} 111 \cdots\right\}
\end{aligned}
$$

where $a_{i} \in\{0,2\}$ for $i=1,2, \cdots, m-1$.

For each nonnegative integer $n$, let $P_{2 n}$ and $P_{2 n+1}$ denote the following partitions of $[0,1]$.

$$
\begin{aligned}
P_{2 n} & =\left\{\bigcup_{k=0}^{n}\left[M_{k} \cup N_{k}\right]\right\} \cup\left\{\bigcup_{k=0}^{n} Q_{k}\right\} \\
P_{2 n+1} & =P_{2 n} \cup Q_{n+1} .
\end{aligned}
$$

Then if $p \in \Delta(1)$, it may be shown that

(1) $\left\|A \int_{0}^{1} T\left(\left[f ; P_{2 n}\right](x)\right) p d x-A \int_{0}^{1} T\left(\left[f ; P_{2 n+1}\right](x)\right) p d x\right\|=0$

(2) $\| A \int_{0}^{1} T\left(\left[f ; P_{2 n+1}\right](x)\right) p d x-A \int_{0}^{1} T\left(\left[f ; P_{\Sigma n+2}\right](x) p d x \| \leqq \frac{M^{2} 2^{n+1}}{2^{n}+3^{n}}\right.$.

Where $M$ is a number so that

(3) $M x \geqq\|T(x) p-p\| \quad x \in[0,2]$ and

(4) $M \geqq\|T(x) p\| \quad x \in[0,2]$.

Thus $\left\{A \int_{0}^{1} T\left(\left[f ; P_{n}\right](x)\right) p d x\right\}_{n=1}^{\infty}$ is a Cauchy sequence in $S$. Theorem 4 implies $\int_{0}^{1} T\left(f^{\prime}(x)\right) p d x$ is in $D(A)$ since $\left\{\left[f ; P_{n}\right]\right\}_{n=1}^{\infty}$ converges uniformly to $f$ on $[a, b]$.

REMARK ON EXAMPLE 4. If $t \in([0,1]-C) \cup\left(\bigcup_{n=0}^{\infty} P_{n}\right)$, the above technique may be used to show that $\int_{0}^{t} T(f(x)) p d x$ is in $D(A)$. This is done by defining the following partitions $P_{n}^{\prime}$ of $[0, t]$. Let

\footnotetext{
${ }^{1}(3.0222 \cdots)$ denotes the triadic respresentation of $1 / 3$, etc.
} 


$$
P_{n}^{\prime}=\left(P_{n} \cap[0, t]\right) \cup\{t\}
$$

for each nonnegative integer $n$. If $t \in\left(C-\bigcup_{n=0}^{\infty} P_{n}\right)$ the following theorem may be used to show that $\int_{0}^{t} T(f(x)) p d x$ is in $D(A)$.

TheOREM 7. Suppose $0 \leqq a<b, p \in \Delta(1)$ and $f$ is a continuous, nonnegative, strictly monotone real valued function defined on $[a, b]$. Then there is a number $M$ so that

$$
\left\|A \int_{c}^{d} T([f ; P](x)) p d x\right\| \leqq(d-c) M
$$

for each partition $P$ of each subinterval $[c, d]$ of $[a, b]$.

Proof. The proof of Theorem 7 follows from Example 1, the fact that $T(x) p$ is a continuous function of $x$, on $(0, \infty)$ and the fact that the infinitesimal generator $A$ is linear.

\section{REFERENCES}

1. E. Hille and J. D. Tamarkin, Remarks on a known example of monotone continuous function, Amer. Math. Monthly 36 (1929), 255-64.

2. E. C. Titchmarsh, The Theory of Functions, 2nd edition, Oxford University Press, Amen House, London, 1939.

Received Feburary 26, 1970.

TEXAs A \& M UNIVERSITy 



\section{PACIFIC JOURNAL OF MATHEMATICS}

\section{EDITORS}

\author{
H. SAMELSON \\ Stanford University \\ Stanford, California 94305

\section{Richard Pierce} \\ University of Washington \\ Seattle, Washington 98105
}

J. DugundJI

Department of Mathematics

University of Southern California

Los Angeles, California 90007

RichaRd ARENS

University of California

Los Angeles, California 90024

\section{ASSOCIATE EDITORS}
E. F. BECKENBACH
B. H. NeUMANN
F. WOLE
K. YoshidA

\section{SUPPORTING INSTITUTIONS}

\author{
UNIVERSITY OF BRITISH COLUMBIA \\ CALIFORNIA INSTITUTE OF TECHNOLOGY \\ UNIVERSITY OF CALIFORNIA \\ MONTANA STATE UNIVERSITY \\ UNIVERSITY OF NEVADA \\ NEW MEXICO STATE UNIVERSITY \\ OREGON STATE UNIVERSITY \\ UNIVERSITY OF OREGON \\ OSAKA UNIVERSITY \\ UNIVERSITY OF SOUTHERN CALIFORNIA
}

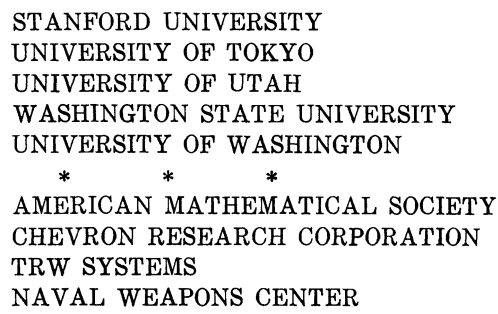

The Supporting Institutions listed above contribute to the cost of publication of this Journal, but they are not owners or publishers and have no responsibility for its content or policies.

Mathematical papers intended for publication in the Pacific Journal of Mathematics should be in typed form or offset-reproduced, (not dittoed), double spaced with large margins. Underline Greek letters in red, German in green, and script in blue. The first paragraph or two must be capable of being used separately as a synopsis of the entire paper. The editorial "we" must not be used in the synopsis, and items of the bibliography should not be cited there unless absolutely necessary, in which case they must be identified by author and Journal, rather than by item number. Manuscripts, in duplicate if possible, may be sent to any one of the four editors. Please classify according to the scheme of Math. Rev. Index to Vol. 39. All other communications to the editors should be addressed to the managing editor, Richard Arens, University of California, Los Angeles, California, 90024.

50 reprints are provided free for each article; additional copies may be obtained at cost in multiples of 50 .

The Pacific Journal of Mathematics is published monthly. Effective with Volume 16 the price per volume (3 numbers) is $\$ 8.00$; single issues, $\$ 3.00$. Special price for current issues to individual faculty members of supporting institutions and to individual members of the American Mathematical Society: $\$ 4.00$ per volume; single issues $\$ 1.50$. Back numbers are available.

Subscriptions, orders for back numbers, and changes of address should be sent to Pacific Journal of Mathematics, 103 Highland Boulevard, Berkeley, California, 94708.

PUBLISHED BY PACIFIC JOURNAL OF MATHEMATICS, A NON-PROFIT CORPORATION

Printed at Kokusai Bunken Insatsusha (International Academic Printing Co., Ltd.), 7-17, Fuj̣imi 2-chome, Chiyoda-ku, Tokyo, Japan. 


\section{Pacific Journal of Mathematics}

\section{Vol. 35, No. $2 \quad$ October, 1970}

Valentin Danilovich Belousov and Palaniappan L. Kannappan, Generalized Bol functional equation .................................... 259

Charles Morgan Biles, Gelfand and Wallman-type compactifications ........... 267

Louis Harvey Blake, A generalization of martingales and two consequent convergence theorems .................................... 279

Dennis K. Burke, On p-spaces and $w \Delta$-spaces..................... 285

John Ben Butler, Jr., Almost smooth perturbations of self-adjoint operators . . . . . . 297

Michael James Cambern, Isomorphisms of $C_{0}(Y)$ onto $C(X) \ldots \ldots \ldots \ldots \ldots . \ldots 307$

David Edwin Cook, A conditionally compact point set with noncompact closure ... 313

Timothy Edwin Cramer, Countable Boolean algebras as subalgebras and homomorphs .........................................

John R. Edwards and Stanley G. Wayment, A v-integral representation for linear operators on spaces of continuous functions with values in topological vector spaces.............................................

Mary Rodriguez Embry, Similarities involving normal operators on Hilbert

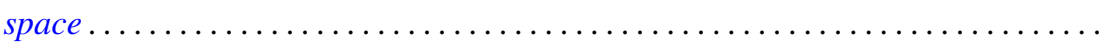

Lynn Harry Erbe, Oscillation theorems for second order linear differential

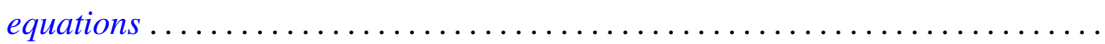

William James Firey, Local behaviour of area functions of convex bodies .......... Joe Wayne Fisher, The primary decomposition theory for modules ..............

Gerald Seymour Garfinkel, Generic splitting algebras for Pic ..................

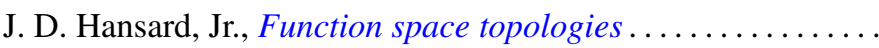

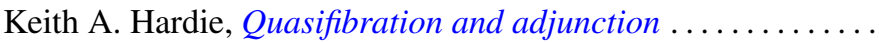

G. Hochschild, Coverings of pro-affine algebraic groups ...........

Gerald L. Itzkowitz, On nets of contractive maps in uniform spaces ..

381

389

399

417

Melven Robert Krom and Myren Laurance Krom, Groups with free nonabelian subgroups....................................

James Robert Kuttler, Upper and lower bounds for eigenvalues by finite differences ......................................

Dany Leviatan, A new approach to representation theory for convolution transforms . . .

Richard Beech Mansfield, Perfect subsets of definable sets of real numbers ...

Brenda MacGibbon, A necessary and sufficient condition for the embedding of a

Lindelof space in a Hausdorff $\mathscr{H} \sigma$ space ..................

David G. Mead and B. D. McLemore, Ritt's question on the Wronskian ....

Edward Yoshio Mikami, Focal points in a control problem .....

Paul G. Miller, Characterizing the distributions of three independent n-dimensional random variables, $X_{1}, X_{2}, X_{3}$, having analytic characteristic functions by the joint distribution of $\left(X_{1}+X_{3}, X_{2}+X_{3}\right)$. . .

P. Rosenthal, On the Bergman integral operator for an elliptic partial differential equation with a singular coefficient....

Douglas B. Smith, On the number of finitely generated $O$-group 